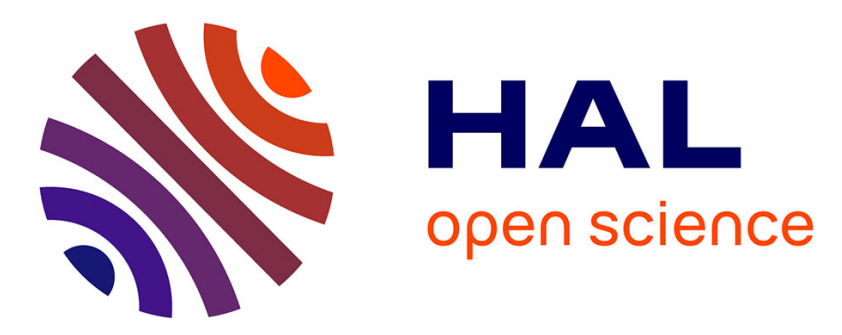

\title{
Amine functionalized SU-8 layer guiding Love mode surface acoustic wave
}

\author{
L. El Fissi, J.-M. Fried, F. Cherioux, S. Ballandras
}

\section{To cite this version:}

L. El Fissi, J.-M. Fried, F. Cherioux, S. Ballandras. Amine functionalized SU-8 layer guiding Love mode surface acoustic wave. Sensors and Actuators B: Chemical, 2010, 144, pp.23-26. 10.1016/j.snb.2009.09.011. hal-00436712

\section{HAL Id: hal-00436712 \\ https://hal.science/hal-00436712}

Submitted on 9 Apr 2021

HAL is a multi-disciplinary open access archive for the deposit and dissemination of scientific research documents, whether they are published or not. The documents may come from teaching and research institutions in France or abroad, or from public or private research centers.
L'archive ouverte pluridisciplinaire HAL, est destinée au dépôt et à la diffusion de documents scientifiques de niveau recherche, publiés ou non, émanant des établissements d'enseignement et de recherche français ou étrangers, des laboratoires publics ou privés. 


\section{Amine functionalized SU-8 layer guiding Love mode}

\section{surface acoustic wave}

Lamia El Fissi, ${ }^{1}$ Jean-Michel Friedt, ${ }^{1, *}$ Frédéric Chérioux, ${ }^{2}$ and Sylvain Ballandras ${ }^{2}$

${ }^{1}$ Senseor, 32 Avenue de l'Observatoire, F-25044 BESANCON cedex, FRANCE

${ }^{2}$ Institut FEMTO-ST, CNRS, Université de Franche-Comte, ENSMM, 32 Avenue de l'Observatoire, F25044 BESANCON cedex, FRANCE

RECEIVED DATE (to be automatically inserted after your manuscript is accepted if required according to the journal that you are submitting your paper to)

CORRESPONDING AUTHOR FOOTNOTE Corresponding author. Tel (++) 33381853963 E-mail: jmfriedt@femto-st.fr

ABSTRACT. The chemical functionalization of SU-8 photoresist with amine-ended silanes is demonstrated. The resulting active layer, coated on a quartz substrate, is used for propagating guided surface acoustic waves: its acoustic properties are used for the development of a chemical sensor for in situ analysis of aqueous solutions. The analytical principle is demonstrated by measuring with time resolution the binding of organometallic complexes of molar weight in the $250 \mathrm{~g} / \mathrm{mol}$ range. The acoustic signal is interpreted as a pure mass effect, with a non selective detection limit of the sensor of $60 \mathrm{ng} / \mathrm{cm}^{2}$.

KEYWORDS: sensor, surface acoustic wave, Love mode, packaging, micro-fluidics 


\section{Introduction}

Epoxy-based SU-8, initially developed by IBM as a high-contrast, negative photoresist, has found increasing use as a structural component in devices [1]. SU-8 quickly gained popularity in the electronics industry as a photoresist for micromachining and microelectronic applications because of its compatibility with conventional microfabrication techniques and its ability to produce high-aspect-ratio microstructures [2]. SU-8 has been intensively used as a photolithographically defined film to produce free-standing features in MEMS[3], bioMEMS[4] and microfluidics devices [5]. In most cases, the SU-

8 is only used as a template, a mere structural layer (walls, channels) or for packaging. The reduction of the number of fabrication steps is often a major factor of efficiency in industrial fabrication. In the case of guided acoustic wave sensors, the conventional pair of thick PECVD silicon dioxide layer and a photoresist layer acting as, respectively chemical sensor and microfluidic device, would be advantageously replaced by a single polymer-based system providing both functions. Nevertheless, there are still challenges to use SU-8 directly as the sensitive layer, the transducer, the microfluidic system and the packaging agent in an acoustic sensor, the two main ones being i) to develop a practical way to functionalize SU-8 and ii) to determine the acoustic properties of a thin SU-8 layer.

The general context of this work is associated with the development of direct detection sensors: such devices provide electric signal changes resulting from the adsorption of molecules to be detected on a surface. The transducer used for converting the physical signal associated with the adsorption is either optical (surface plasmon resonance or guided evanescent wave coupling angle change due to local optical index variations) or acoustic (quartz crystal microbalance or surface acoustic wave sensor in which the adsorbed layer induces an acoustic wave propagation delay) [6]. Specifically, surface acoustic wave (SAW) sensors are based on the measurement of the velocity and acoustic losses of an acoustic wave generated by interdigitated structures (IDTs) patterned on a piezoelectric substrate. Love mode acoustic wave sensors use a guided shear acoustic wave capable to withstand the presence of a liquid medium on the wave propagation path. The quantitative analysis provides, thanks to the time resolution, adsorption or reaction kinetics as well as adsorbed mass and viscoelastic characteristics. The 
main packaging issue then is to avoid coating the IDTs with the solvent since the large dielectric constant of water leads to a strong efficiency loss of the electric energy coupling in the piezoelectric substrate.

In this paper, we develop a method to functionalize this material by alkoxysilane and to determine the acoustic properties of a SU-8 layer. The acoustic properties and the functionalization of a SU-8 thin layer are exploited to realize an acoustic sensor. Based on the grafting of a specific self-assembled monolayer (SAM) on the SU-8 guiding layer, this device can be used to determine in real time the concentration of ruthenium and rhodium complexes in an aqueous solution.

\section{Experimental section}

\section{Acoustic waves sensors}

We have developed a Love mode surface acoustic wave sensor, in which a shear wave is confined in a guiding layer. The wave guide is fabricated by depositing a $1 \mu \mathrm{m}$ thick SU-8 layer on AT-cut quartz with wave propagation along the rotated $\mathrm{Z}$ axis. The waves are launched and detected using double-digit interdigitated transducers (IDT) patterned in a $200 \mathrm{~nm}$ thick evaporated Al layer. The resulting sensor is thus made of 50 pairs of IDTs separated by a cavity $3.2 \mathrm{~mm}$ long and $3.5 \mathrm{~mm}$ wide. The acoustic aperture is $3.5 \mathrm{~mm}$ (See Figure 1). A major difficulty in using polymer guiding layers rather than the commonly used silicon dioxide arises from the higher acoustic losses. On the other hand polymer guiding layers display a large difference in acoustic velocity in comparison to quartz and hence improved acoustic confinement and thus increased mass sensitivity. Also, thick $(>1 \mu \mathrm{m})$ guiding layers are easily fabricated in an industrial fabrication perspective. Following polymerisation of the $1 \mu \mathrm{m}$ thick guiding layer, a $150 \mu \mathrm{m}$ thick layer is deposited and patterned in order to define the fluidic channels defining the chemical reaction cavity (above the wave propagation path) containing the fluid to be analyzed, while preventing the solution from reaching the interdigitated transducers [7]. 


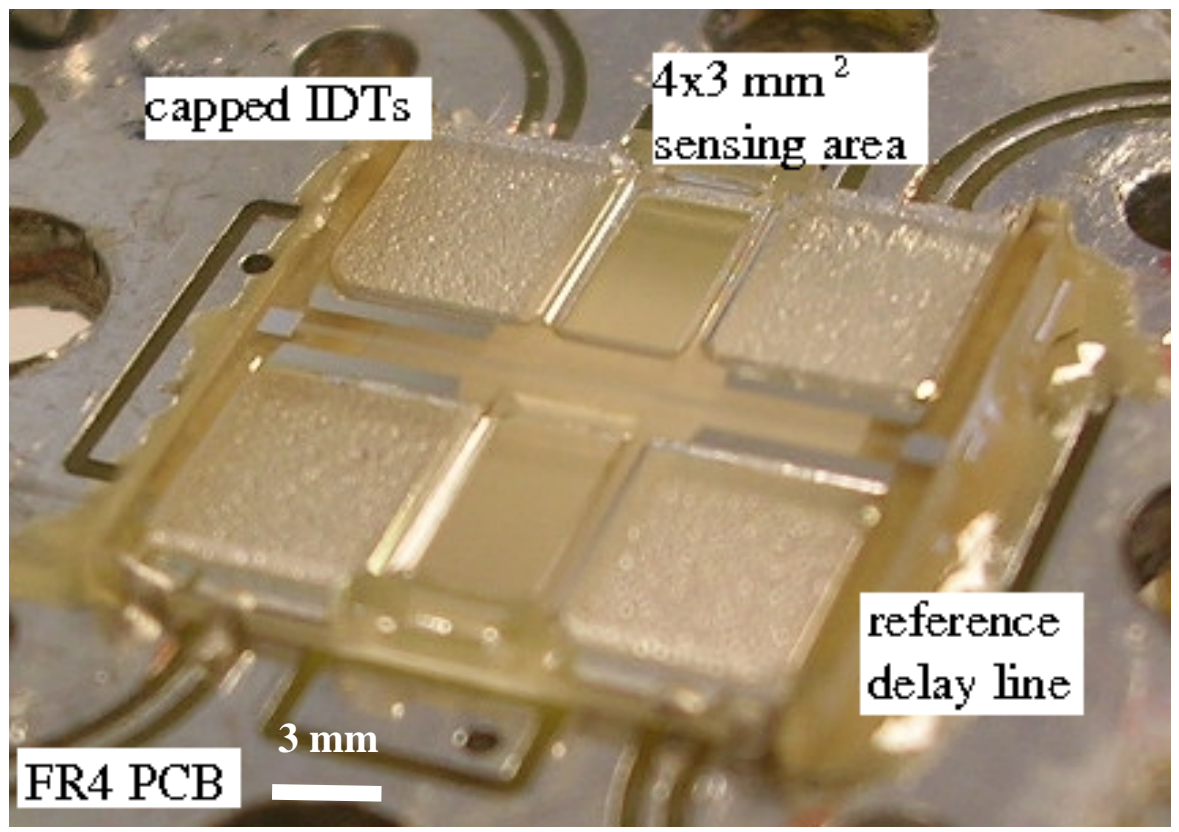

Figure 1. Picture of the SAW device.

This fluidic network is tightly sealed with glass slides joining the walls delimiting the IDTs regions: by avoiding liquid over the transduction area, the electrical coupling in the quartz substrate is still efficient even during measurement of a high dielectric constant liquid sample, while leaving a $7 \mu$ open well over the sensing area in which the sample to be analyzed will be deposited.

The acoustic properties of the acoustic delay line is monitored at a rate of $1 \mathrm{~Hz}$ using a GPIB controlled Rohde \& Schwartz ZVC network analyzer. The phase and magnitude of the $\mathrm{S}_{21}$ transmission coefficient within the band pass frequency range are recorded for post-processing.

\section{Materials}

All reagents and solvents were purchased (Aldrich) and used as received. Dinuclear dichloro complexes $\left[\mathrm{Ru}\left(\eta^{6}-\mathrm{C}_{6} \mathrm{H}_{6}\right) \mathrm{Cl}_{2}\right]_{2}$ and $\left.\mathrm{Ru}\left(\eta^{5}-\mathrm{C}_{5} \mathrm{Me}_{5}\right) \mathrm{Cl}_{2}\right]_{2}$ were synthesized by previously described methods [8].

\section{Grafting of SAMs on SU-8}

The SU-8 guiding layer was plasma treated under ozone for one hour. This oxidising treatment induces the formation of hydroxy functions at the surface of the SU-8 guiding layer. Monolayers were 
prepared by immersion of cleaned substrates in a $100 \mu \mathrm{M}$ toluene solution (100 ml) of 3(dimethoxymethylsilyl)-1-propylamine for 12-hours at room temperature. Then, the substrates were rinsed with large amounts of toluene and baked for $1 \mathrm{~h}$ at $110^{\circ} \mathrm{C}$.

\section{Results and Discussions}

\section{SU-8 functionalization}

According to the literature, the surface of SU-8 can be activated either by an oxygen plasma, [9] reaction with ethanolamine [10] or by UV-ozone treatement [11]. The mechanism involved in these methods is to ensure the formation of free reactive radicals on a surface which can then be used for the grafting of new functionalities to surface of the target material (e. g. SU-8). Our approach is based on the UV-ozone treatment of the SU-8 guiding layer for grafting an amino-ended organosilane monolayer (Figure 2).

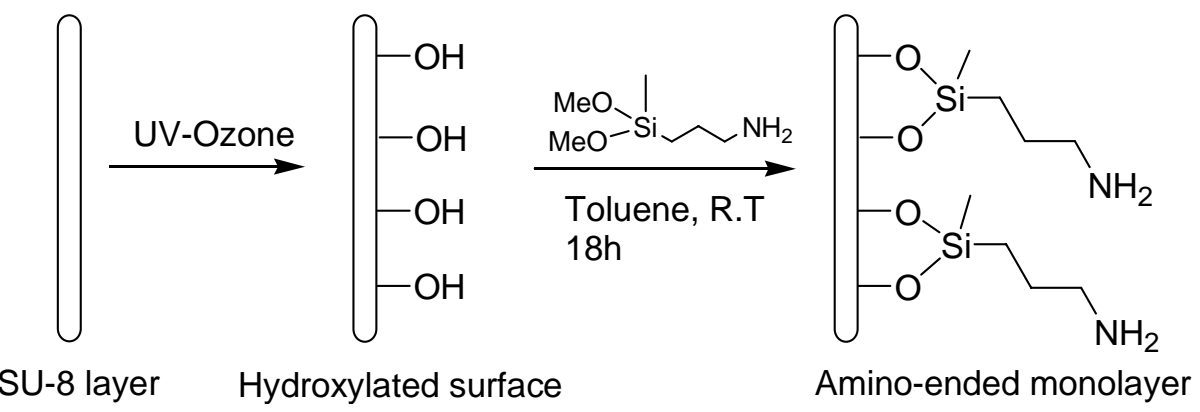

Figure 2. Functionalization of SU-8 layer by amino-ended monolayer.

This type of precursors (i.e. dialkoxysilane derivative) has been chosen because it is known to lead to very compact monolayers [12]. Reactants bearing two alkoxysilane functions are the best approach to optimize the epitaxial growth of the SAMs on silica layer. The IV-valence of silicon is respected, leading to solid grafting because one molecule constituting the SAMs is covalently bounded with two silicon atoms of the substrate. The formation of aggregates and multilayers is annihilated thanks to the absence of trifunctionnal functions as would be the case when using trialkoxysilane derivatives. This is a key-point in the view of obtaining an efficient SAW sensor, because the formation of a thin sensitive 
layer on the SU-8 guiding layer ensures that the SAW is not strongly attenuated as would happen with larger thicknesses. The functionalization has been confirmed by XPS experiments on the sensitive layer of our sensor. Peaks corresponding to Si-O, Si-C and C-N binding energies are detected at 103.5, 284.6 and $398.8 \mathrm{eV}$ respectively. For example, the N1s peak is centred at $398.8 \mathrm{eV}$ which can be assigned to the amino moiety as it has been previously described in the case of the functionalization of polyethylene-terephtalate by 3-aminopropyl-triethoxysilane [13].

\section{Application of SU-8 as a guiding layer for acoustic sensing application}

In order to check whether the modified SU-8 film can be used as a guiding Love mode SAW, this layer has been coated on an acoustic device and previously characterized [14].

The organometallic compounds selected for tests are obtained after the hydrolysis of $\left[\mathrm{Ru}\left(\eta^{6}\right.\right.$ $\left.\left.\mathrm{C}_{6} \mathrm{H}_{6}\right) \mathrm{Cl}_{2}\right]_{2}$ and $\left.\mathrm{Rh}\left(\eta^{5}-\mathrm{C}_{5} \mathrm{Me}_{5}\right) \mathrm{Cl}_{2}\right]_{2}$, which arise into $\left[\mathrm{Ru}\left(\eta^{6}-\mathrm{C}_{6} \mathrm{H}_{6}\right)\left(\mathrm{H}_{2} \mathrm{O}\right)_{3}\right]^{2+}$ and $\mathrm{Rh}\left(\eta^{5}-\right.$ $\left.\left.\mathrm{C}_{5} \mathrm{Me}_{5}\right)\left(\mathrm{H}_{2} \mathrm{O}\right)_{3}\right]^{2+}$ cations, respectively [15]. These cations react with aliphatic amine, $\mathrm{R}-\mathrm{NH}_{2}$, to give cationic complexes of the type $\left[\mathrm{Ru}\left(\eta^{6}-\mathrm{C}_{6} \mathrm{H}_{6}\right)\left(\mathrm{H}_{2} \mathrm{O}\right)_{3-\mathrm{x}}\left(\mathrm{R}-\mathrm{NH}_{2}\right)_{\mathrm{x}}\right]^{2+}$ and $\mathrm{Rh}\left(\eta^{5}-\mathrm{C}_{5} \mathrm{Me}_{5}\right)\left(\mathrm{H}_{2} \mathrm{O}\right)_{3-\mathrm{x}}(\mathrm{R}-$ $\left.\left.\mathrm{NH}_{2}\right)_{\mathrm{x}}\right]^{2+}$ with $\mathrm{x}=1,2$ or 3 , respectively. An aqueous solution of $\left[\mathrm{Ru}\left(\eta^{6}-\mathrm{C}_{6} \mathrm{H}_{6}\right) \mathrm{Cl}_{2}\right]_{2}$ and $\mathrm{Rh}\left(\eta^{5}-\right.$ $\left.\left.\mathrm{C}_{5} \mathrm{Me}_{5}\right) \mathrm{Cl}_{2}\right]_{2}$, (concentration: $1 \mathrm{~g} / \mathrm{l}$ ) is freshly prepared and one droplet $(10 \mu \mathrm{l}$ ) is deposited on the SU-8 layer while the magnitude and phase of the acoustic signal at a fixed frequency are monitored. The solution stands still over the sensing area (open well configuration). The open cuvette was then thoroughly rinsed 3 times using DI water in order to remove all the free organometallic species in the water solution. Figures 3 and 4 present the results of these experiments. The blank experiment in which the sensing area with no prior chemical functionalization is exposed to the same analyte does not display significant phase or magnitude shift within measurement uncertainties. 

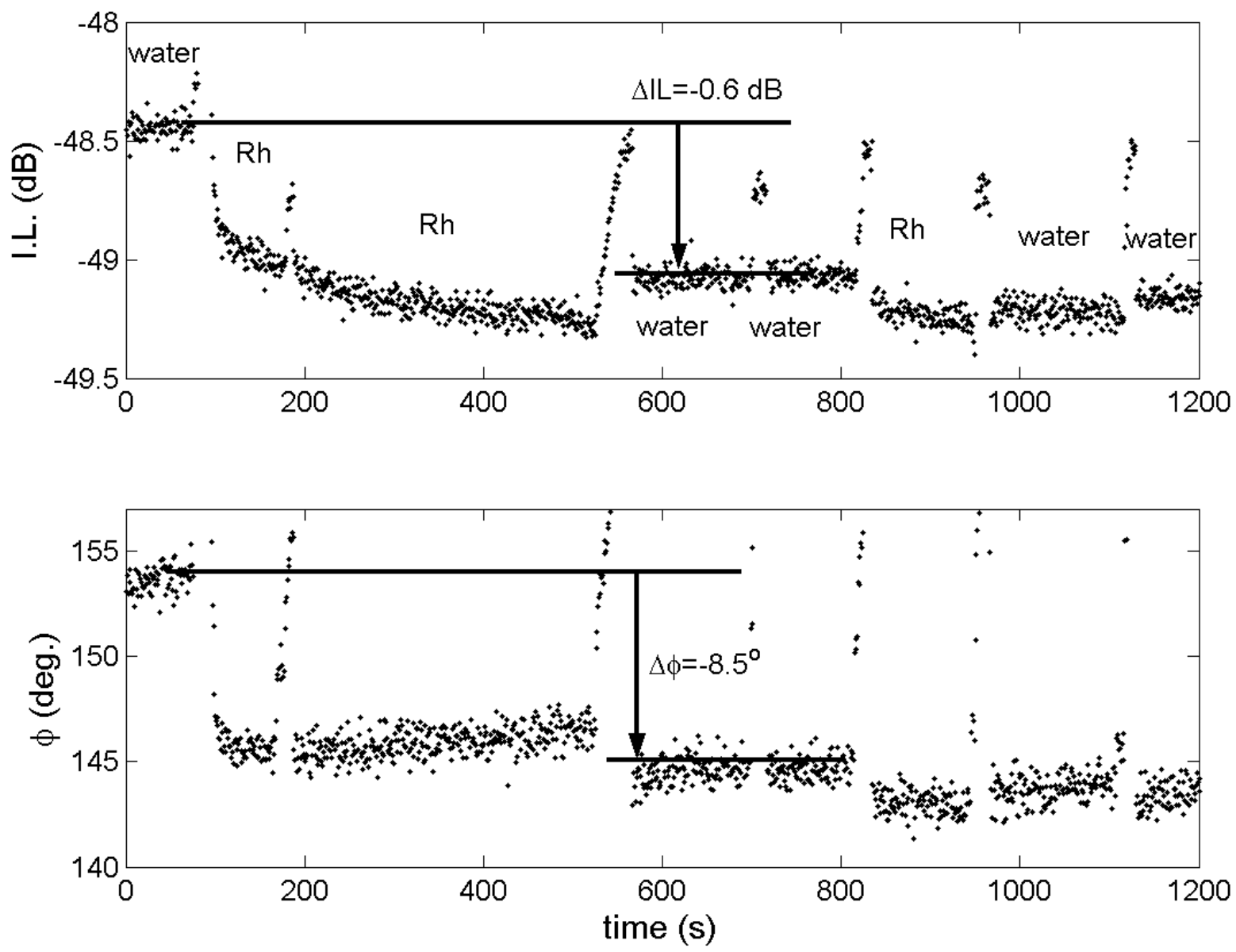

Figure 3. Time resolved measurements of the insertion loss (I.L., top) and phase shift (bottom) of a 125 MHz Love mode acoustic wave sensor with a SU-8 guiding layer functionalized by amino-ended monolayer upon adsorption of an Rh organometallic complex. 

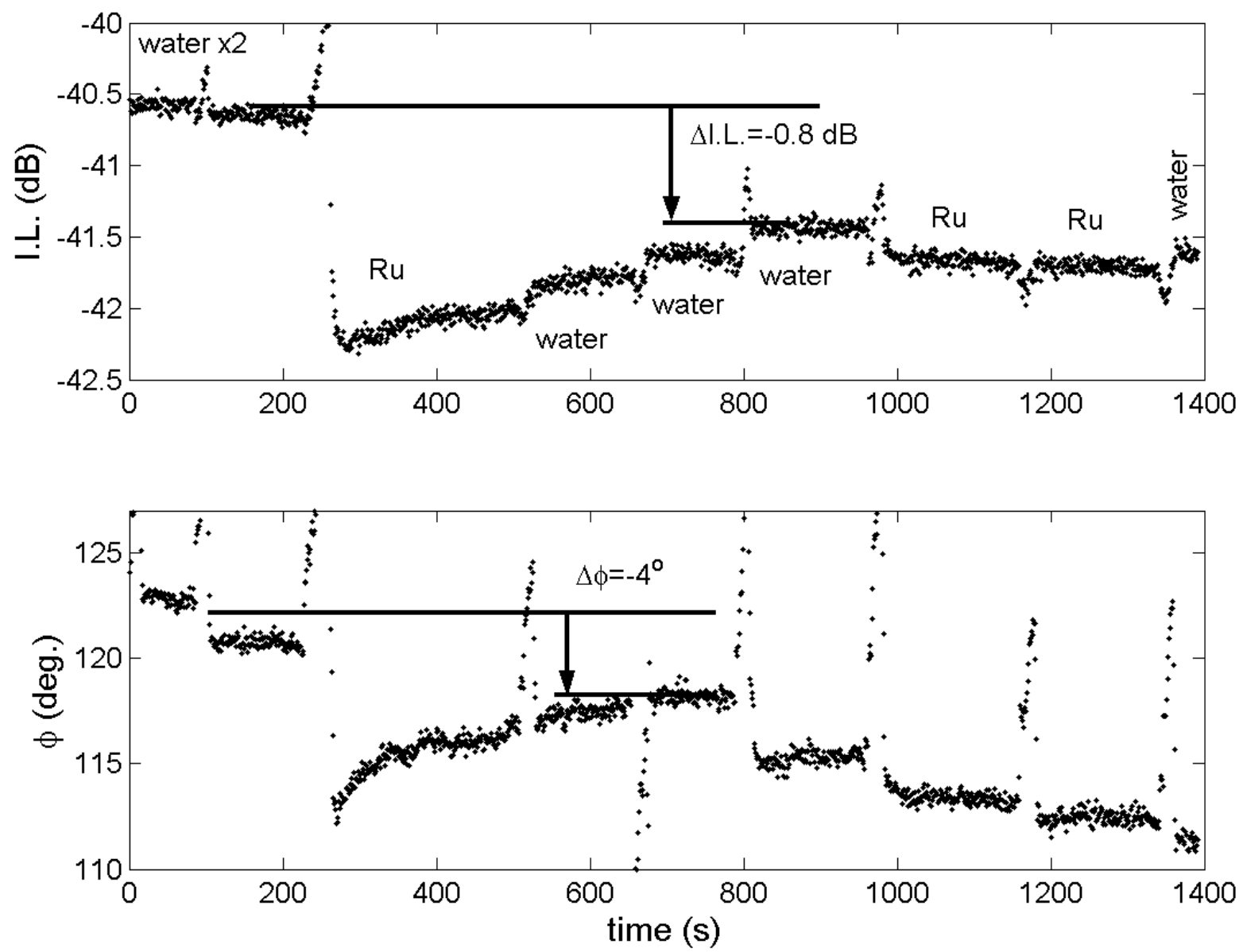

Figure 4. Time resolved measurements of the insertion loss (I.L., top) and phase shift (bottom) of a $125 \mathrm{MHz}$ Love mode acoustic wave sensor with a SU-8 guiding layer functionalized by amino-ended monolayer upon adsorption of an Ru organometallic complex.

After obtaining a stable baseline using deionized water, the solution containing the organometallic complex (Rh: Figure 3 and Ru: Figure 4) is deposited over the sensing area. Following adsorption, the surface is thoroughly rinsed, before the same organometallic complex containing solution is again deposited on the surface to verify that the surface was saturated during the first reaction step and that no further signal change is observed. Finally, the surface is rinsed to achieve a stable final baseline. A phase change (see Figures 3 and 4) is noted, associated with the velocity shift generally attributed to a mass increase. The magnitude of the transmitted energy exhibits changes of the order of 0.5 to $1 \mathrm{~dB}$ (see 
Figures 3 and 4), corresponding to a few $10^{-2} \mathrm{~dB} / \lambda$. Such a magnitude change may be associated with viscoelastic or dielectric loss variations occurring due to the film adsorption [16]. We work here with a dielectric guiding layer without metallic coating on the sensing area which would act as a Faraday shield. Hence, the acoustic wave propagation is not only affected by a mass adsorption but also by permittivity changes of the layer adsorbed on the surface.

In this context, acoustic direct detection sensors are not only sensitive to gravimetric effects but have also been shown to be affected by dielectic or viscoelastic effects [17]. The detection limit of Love mode SAW sensors is in the $60 \mathrm{ng} / \mathrm{cm}^{2}$ range as deduced from the intrinsic gravimetric sensitivity of the transducer [18] $\left(250 \mathrm{~cm}^{2} / \mathrm{g}\right.$,), the phase-frequency slope $\mathrm{d} \phi / \mathrm{df}=360 \cdot \mathrm{L} / \mathrm{V}=5 \cdot 10-4 \% / \mathrm{Hz} \quad(\mathrm{L}=7 \mathrm{~mm}$ the acoustic cavity length, $V=5000 \mathrm{~m} / \mathrm{s}$ the phase velocity) and the typical phase measurement noise of network analyzers (0.3 degrees): such transducers were used for detecting thin films such as adsorbed protein or polymer films.

The adsorbed mass density of the saturated organometallic complexes monolayer is estimated to be 180 and $230 \mathrm{ng} / \mathrm{cm}^{2}$ for Ru and Rh complexes respectively as follows: there are 5 anchorage sites [11] (i. e. aminosilane) by $\mathrm{nm}^{2}$ and the molecular weight of complexes hydrated with two water molecules is $215 \mathrm{~g} / \mathrm{mol}$ and $274 \mathrm{~g} / \mathrm{mol}$ for Ru and Rh complexes respectively. This mass density accounts by more than a factor of three above the detection limit of the sensor $\left(60 \mathrm{ng} / \mathrm{cm}^{2}\right)$. Furthermore, a mass of 180 or $230 \mathrm{ng} / \mathrm{cm}^{2}$ deposited on a SAW with mass sensitivity $250 \mathrm{~cm}^{2} / \mathrm{g}$ yields a frequency shift of, respectively 5625 and $7200 \mathrm{~Hz}$. This frequency shifts can be converted to phase shift of respectively 2.8 and 3.6 degrees thanks to a phase to frequency slope of $5.10-4 \% / H z$. These values are close to the experimental observations (Figs. 3 and 4). Since thin films will hardly provide significant viscoelastic interactions with the acoustic wave, it is assumed that an additional contribution due to the permittivity of the adsorbed layer interfers.

\section{XPS analysis}

The target analytes of our acoustic sensors are organometallic species containing one ruthenium or one rhodium atom because these elements are heavy enough to be detected with a SAW sensor, and also 
significantly because these elements provide unique signatures during XPS analysis: the associated signals provide unambiguous information on the binding of organometallic species and hence of the amine functionalization of the surface.

In order to definitively prove that the species which have been detected by the acoustic sensor are effectively the expected organometallic derivatives of Ruthenium or Rhodium, XPS investigations of the sensitive layer of the sensor after treatment by aqueous solutions of $\left[\mathrm{Ru}\left(\eta^{6}-\mathrm{C}_{6} \mathrm{H}_{6}\right) \mathrm{Cl}_{2}\right]_{2}$ and $\mathrm{Rh}\left(\eta^{5}\right.$ $\left.\left.\mathrm{C}_{5} \mathrm{Me}_{5}\right) \mathrm{Cl}_{2}\right]_{2}$ have been performed.
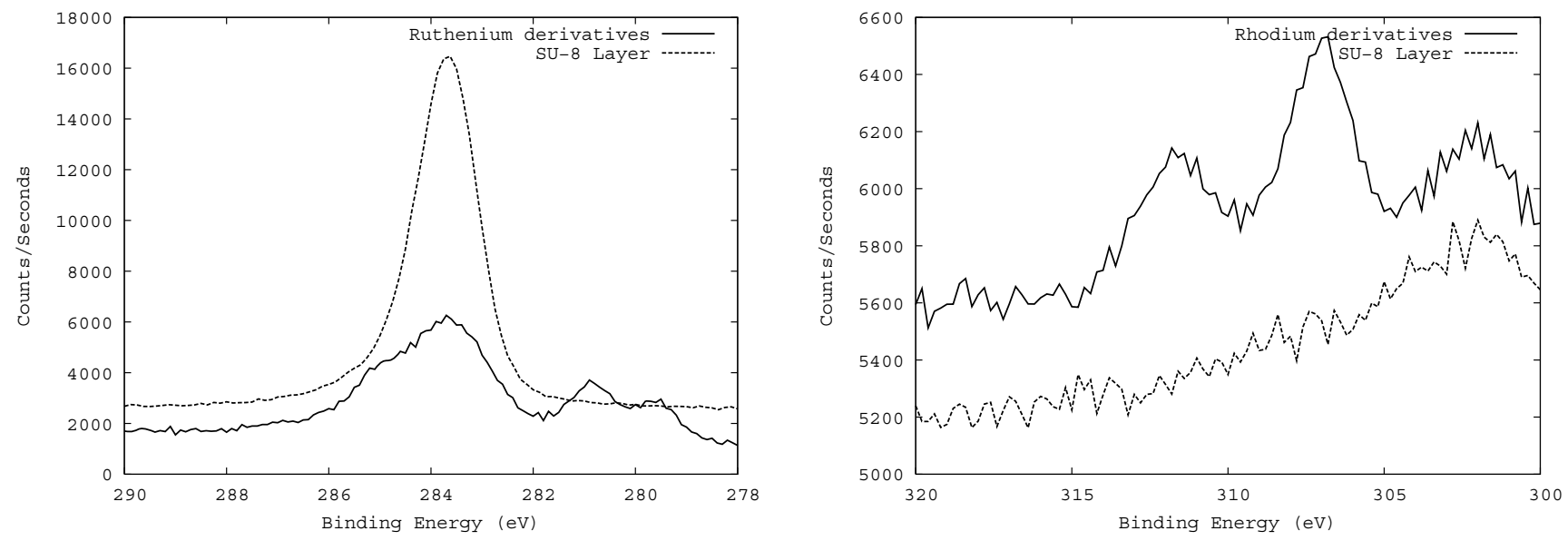

Figure 5. XPS spectra of sensitive layers of acoustic sensors without functionalization of the SU-8 guiding layer (dashed line) and after functionalization with amino-ended groups and treatment with an aqueous solution of $\left[\mathrm{Ru}\left(\eta^{6}-\mathrm{C}_{6} \mathrm{H}_{6}\right) \mathrm{Cl}_{2}\right]_{2}$ (left) and $\left[\mathrm{Rh}\left(\eta^{5}-\mathrm{C}_{5} \mathrm{Me}_{5}\right) \mathrm{Cl}_{2}\right]_{2}$ (right) of the SU-8 guiding layer (line).

In the case of ruthenium derivative, the $\mathrm{Ru} 3 \mathrm{~d}_{5 / 2}$ peak is observed at $280.9 \mathrm{eV}$ (Fig.5, left), which is close to the literature values of RuII in other complexes [19], that is, $279.5-281.8 \mathrm{eV}$ for $\left[\mathrm{Ru}\left(\mathrm{NH}_{3}\right) \mathrm{L}\right]^{2+}$ [20]. Moreover, in this range of energy, the carbon peak (C1s) was detected at 283.9 eV, which can be assigned to the $\mathrm{C}-\mathrm{H}$ due to organic moieties. In the case of Rhodium species, the $\mathrm{Rh} 3 \mathrm{~d}_{5 / 2}$ and $\mathrm{Rh} 3 \mathrm{~d}_{3 / 2}$ peaks are respectively seen at 308.1 and $312.0 \mathrm{eV}$, which are close to the literature values of RhI in other complexes [21, 22]. Figure 5 demonstrates that the functionalization process is effective since a 
significant and irreversible signal is observed only following SU-8 functionalization with amineterminated silanes.

These results hint at potential use of such sensors in real time industrial product control where selectivity is not an issue. For example, the metal contamination of target materials, after olefin metathesis reactions, can lead to side-reactions or dangerous doping in the context of pharmaceutical synthesis or nanoelectronic. The best reported work exhibit a concentration of ruthenium derivatives close to $60 \mathrm{ppm}$ which is still above the level required for pharmaceutical applications (ca. 10-20 ppm) [23]. The main methods which are used to determine the amounts of metals are atomic absorption spectroscopy (AAS), X-ray fluorescence, and plasma emission methods.

\section{Conclusion}

The acoustic properties and the functionalization of a SU-8 thin layer are investigated. These properties have been applied to develop an innovative and original chemical sensor which is based on the propagation of a Love mode surface acoustic wave in an SU-8 layer. The functionalization of this layer by organosilane was demonstrated via the detection of aqueous ruthenium or rhodium organometallic complexes. All experiments have been further assessed by XPS analysis of the surface. This type of functionalization opens further opportunities for such a sensor since it lays the basic functionalization steps towards the detection of metallic nanoparticles as well as of biological species.

\section{REFERENCES.}

[1] Shaw, J. M.; Gelorme, J. D.; Labianca, N. C.; Conley, W. E.; Holmes, S. J. IBM J. Res. Dev. 1997, 41, 81-94.

[2] Lorentz, H.; Despont, M.; Fahrni, N.; Labianca, N.; Renaud, P.; Vettiger, M. J. Micromrech. Microeng. 1997, 7, 121-124. 
[3] Georgel, V.; Verjus, F.; van Grusven, E. C. E.; Poulichet, P.; Lissorgues, G.; Pellet, C.; Chamaly, S.; Bourouina, T. Sens. Actuators A 2008, 142, 185-191.

[4] Desai, S. P.; Taff, B. M.; Voldman, J. Langmuir 2008, 24, 575-581. Salazar, G. T. A.; Wang, Y.; Young, G.; Bachman, M.; Sims, C. E.; li, G. P.; Allbritton, N. L. Anal. Chem. 2007, 79, 682-687.

[5] Lo. R; Meng, E. Sens. Actuators B 2008, 132, 531-539 Pennell, T.; Suchyna, T.; Wang, J.; Heo, J.; Felske, J. D.; Sachs, F.; Hua, S. Z. Anal. Chem. 2008, 80, 2447-2451.

[6] (a) Kanazawa, K. K.; Gordon II, J.G. Anal. Chem. 1985, 57, 1770-1771. (b) Tsortos, A.; Papadakis, G.; Gizeli, E. Biosensors Bioelec. 2008, 24, 842-847. (c) Aung, K. M. M.; Ho, X.; Su, X. Sens. Actuators B. 2008, 131, 371-378.

[7] Francis, L.; Friedt, J.-M.; Bartic, C. Campitelli, A., SPIE proceedings series 2004, 5455, 353-363.

[8] (a) Zelonka, R. A.; Baird, M. C. Can. J. Chem. 1972, 50, 3063-3068. (b) Wang, J. W.; Moseley, K.; Maitlis, P. M. J. Am. Chem. Soc., 1969, 5970-5977. (c) Bennett, M. A.; Smith, A. K. J. Chem. Soc, Dalton Trans. 1974, 233-241.

[9] Tseng, F. G.; Lin, K. H.; Hsu, T. T.; Chieng, C. C. Sens. Actuators A 2004, 111, 107-117.

[10] Nordstrom, M.; Marie, R.; Calleja, M.; Boisen, A. J. Micromrech. Microeng. 2004, 14, 16141617.

[11] Wang, Y.; Bachman, M.; Sims, C. E.; Li, G. P.; Allbriton, N. L. Langmuir 2006, 22, 2719-2725.

[12] Moon, J. H.; Shin, J. W.; Kim, S. Y.; Park, J. W. Langmuir 1996, 12, 4621-4625.

[13] Romaschin, A. D.; Bui, L. N.; Thompson, M., McKeown, N. B.; Kalman, P. G. The Analyst 1993, 118, 463-474. 
[14] a) L. El Fissi, J.-M Friedt, S. Ballandras, IEEE Ultrasonic Symposium 2007, 484-487. b) L. El

Fissi, J.-M Friedt, S. Ballandras, L. Robert, F. Cherioux, IEEE International Frequency Control Symposium 2008, 711-716

[15] Stebler-Rötzthlisberger, M.; Hummel, W.; Pittet, P. A.; Bürgi, H.-B.; Ludi, A.; Merbach, A. E. Inorg. Chem. 1988, 27, 1358-1362.

[16] Thompson, M.; Stone, D.C. in Surface-Launched Acoustic Wave Sensors: Chemical Sensing and Thin-Film Characterization, Wiley-Interscience, 1997.

[17] Banda P. A. in Investigation on surface acoustic wave gas sensors. Application to ozone sensing, PhD Thesis, Royal Melbourne Institute of Technology, 1995.

[18] Friedt, J.-M.; Choi, K.H.; Frederix F.; Campitelli, A. J. Elect. Soc. 2003, 150, H229-H234.

[19] Varughese, B.; Chellamma, S.; Lieberman, M. Langmuir 2002, 18, 7964-7970.

[20] Shepherd, R. E.; Proctor, A.; Henderson, W. W.; Myser, T. K. Inorg. Chem. 1987, 26, 24402444.

[21] Cagnola, E. A.; Quiroga, M. E.; Liprandi D. A., L'Argentièire, P. C. Applied Cat. A 2004, 274, 205-212.

[22] Mendes, F. M. T.; Schmal, M. Applied Cat. A 1997, 151, 393-408.

[23] Garrett, C. E.; Prasad, K. Adv. Synth. Catal. 2004, 346, 889-893. 